Parkhurst, Gregory M., Jason F. Shogren, and David L. Dickinson (2004), Negative Values in Vickrey Auctions. American Journal of Agricultural Economics, 86(1): pp. 222-35. (Feb 2004) Published by Wiley-Blackwell (ISSN: 1467-8276) DOI: 10.1111/j.0092-5853.2004.00574.x The definitive version is available at www.onlinelibrary.wiley.com.

\title{
Negative Values in Vickrey Auctions
}

Gregory M. Parkhurst

Jason F. Shogren

David L. Dickinson

\begin{abstract}
Some people assign negative values for new products sold on laboratory auction blocks (i.e., irradiated meat). We explore bidding behavior in two Vickrey auctions when people have positive and negative induced values for the good. Aggregate bidding in the second-price auction is precise but biased-highest-value positive bidders tend to overstate benefits, whereas lowest-negative bidders understate losses. In contrast, bidding behavior in the random $n$ th-price auction is demand revealing irrespective of induced value, but it is imprecise. Examining on- and off-margin bidding behavior, we cannot conclude that any segments of demand are significantly different than the demand revealing regression line.
\end{abstract}


Researchers use experimental auctions now to help them better understand the potential demand for new or different goods and services (e.g., Fox et al., 1998; Lusk et al.;

Shogren). But some people who participate in these laboratory valuation exercises have negative opinions, and therefore negative values, about many new food products being auctioned, like irradiated meat or genetically modified potatoes. The open question we address herein is whether the presence of negative values affects bidding behavior within the incentive compatible Vickrey-style auctions used in laboratory valuation experiments. Rather than having people bid on new products, we use a classic induced value design that controls preferences to create a testable behavioral benchmark (Smith). Our auction environment has people bidding over a good in which both positive and negative induced values exist within the population of bidders.

We examine the potential bias and precision of bidding behavior for two popular auctions used in laboratory valuation work - the classic Vickrey second-price auction and the random $n$ th-price auction, a mechanism initially designed to engage people with values otherwise below the market-clearing price in the second-price auction (see Shogren et al., 2001). The next section sets the stage for our experiments by discussing the broader context behind negative values and bidding behavior. We then present the details for the experimental design. The next two sections discuss the results, and on- and off-the-margin bidder behavior. We offer concluding remarks in the final section.

\section{Background}

Our experiments were motivated by a broader context on how negative values can affect valuation. Neoteric food products like irradiated pork, growth hormone milk, genetically modified potatoes have conjured up diametrically opposed images for consumers in the 
marketplace. Irradiation to some people means reduced risk from food borne pathogens, but implies "nuclear meat" to others; growth hormones implies more production at lower cost and worries of "cow junkies"; genetic modification means enough cheap food to feed the planet and yet still generates concerns of "frankenfood." Many consumers react positively on net to these ambiguous products, and will pay for them, while others react negatively and would have to be paid to eat them (see, e.g., Buhr et al.). Although supermarkets sell these products on a limited basis (e.g., irradiation) or without explicit labels (e.g., genetic modification), little is still known about the general consumer demand because it remains an open question as to how they will react to these new food technologies. $^{2}$

As a way to learn more about potential consumer choice, researchers have designed a series of laboratory experiments that ask people to reveal their preferences in a real auction in which they spent money and consumed the actual controversial food products. ${ }^{3}$ Experimental methods are designed to isolate and control the market setting to address specific questions on how people value new and controversial food products. These experiments typically used Vickrey's second-price auction to reveal demand. The attraction of the second-price auction is that, in theory, it is demand revealing. A bidder's weakly dominant strategy is to bid his true preferences for the auction good, irrespective of whether his value is on-net positive or negative. A person who bids less than his true value risks foregoing a profitable purchase, whereas someone who overbids risks making negative profits by paying too much for the good.

Researchers recognized that some people who agreed to participate in these auctions might actually have a negative value for the product on the auction block. ${ }^{4}$ They 
might demand that they be paid to eat the product. But rather than allowing for negative bids in the second-price auction, experiments were designed on the presumption that people with negative values would pay nothing and therefore would submit a zero bid (see Fox, Hayes, and Shogren). ${ }^{5}$ Other researchers, however, made a pragmatic choice on a design that first screened and then separated subjects into two groups - those who preferred the new product to the standard product (positive values for new), and those who preferred the typical to the new (negative values for new). ${ }^{6}$ Buhr et al. for example, avoided any questions about negative value bidding behavior for growth hormone pork by separating people by whether they said they preferred normal or growth hormone pork. They then segregated the bidders into two auctions such that each person was bidding for the good they said they preferred. ${ }^{7}$ All bids were either positive or zero.

The question of negative values also has potential implications for current discussion over the valuation of nonmarket public goods. While the method of contingent valuation studies has stirred much debate (e.g., Hanemann; Diamond and Hausman), researchers now realize that environmental externalities may be perceived as either costs or benefits depending on the individual (Clinch and Murphy). ${ }^{8}$ The truncation of respondents' negative valuations in contingent valuation studies would both bias results, and it would also imply flawed policy choices based on such results (Macmillan, Duff, and Elston). While the experiments in this article study private goods, they are timely as an initial controlled exploration into whether allowing positive, zero, and negative bids - in commonly used experimental auction institutions-is successful in promoting accurate demand revelation for all preference possibilities for a product. 
The decision to either truncate bidding at zero or to screen-and-separate prior to bidding was motivated by the fact that no experimental evidence exists on how people actually bid in the second-price auction when they have both positive and negative values. ${ }^{9}$ It is not obvious that people will bid consistently over positive and negative values, with either private or induced values. A substantial literature now exists which suggests people fear a loss more than they desire the equivalent gain (see Camerer). The behavioral observations of loss aversion, alarmist reactions, and the willingness to pay (WTP)-willingness to accept (WTA) gap are manifestations of this asymmetric behavioral reaction to gains and losses Loss aversion type behavior implies that monetary losses associated with switching to an alternative are given greater weight than corresponding gains (see Kahneman and Tversky, 1979, 2000). Alarmist reactions exist when people provided with both positive and negative descriptions about a product act as if they were only given the negative description (see Viscusi). ${ }^{10}$

These findings raise some concern about bidding behavior in laboratory valuation auctions in which negative values could exist. For instance, in a second-price auction, if people with negative values overreact by bidding more negatively to avoid controversial food like irradiated meat, the laboratory results would inflate the potential negative reaction in a market. We address this issue by going back to fundamentals - we design an induced-value experiment to explore how negative values affects bidding behavior within two Vickrey style auctions. The induced value setting provides the cleanest environment to test how negative values can affect bidding behavior because it stays away from the unknown private preferences that arise with actual goods and services. If the auctions fail to induce people to bid rationally here, people should wonder if the 
mechanism have or might fail in non-induced valuation experiments in which we do not know a person's actual value. Consider now the details of our experimental design.

\section{Experimental Design}

We consider bidding behavior within two Vickrey-style auctions - a classic second-price auction and a random $n$ th-price auction (the cut-off bidder is selected at random, i.e., the nth-price rather than the second-price; see Shogren et al., 2001). We use the random nth-price auction to engage bidders whose values fall below the margin of the marketclearing second price. Evidence suggests bidders have less incentive to bid sincerely when they have little chance of winning an auction (see Franciosi et al.).

Our general experimental design follows standard procedures, except we use three sets of positive and negative induced values as the treatments and subjects were assigned

a new induced value in each round (also see Kagel). ${ }^{11}$ Each round had nine steps. Step 1: each bidder received a value sheet that had his or her private resale value for that round. The bidder's resale value is the price the monitor would pay to the bidder if he were the highest bidder. The sets of private values were randomly drawn from a uniform distribution of $[\$-5.00, \$ 5.00]$ in ten-cent increments. We created three sets of private resale values as the treatments: (A) $[-4.7,-3.9,-2.8,-1.5,-1.0,0.2,1.3,2.6,2.9,3.9]$; (B) $[-4.8,-4.4,-1.3,0.8,1.3,1.4,2.9,3.1,3.2,4.4]$; and (C) $[0.3,1.1,2.2,3.5,4.0,5.2,6.3$, 7.6, 7.9, 8.9]. We created treatment $\mathrm{C}$, the all-positive value baseline, by adding $\$ 5$ to each value in treatment A. Each treatment had twenty rounds of bidding such that each bidder had each value twice. Each bidder had a personal and private record sheet to maintain that created a history of past induced values, bids, and profits, and the marketclearing price for previous rounds. 
Step 2: the rules of the auction mechanism were introduced to the bidders. For the second-price auction, subjects were told that the subject with the highest bid would buy one unit of the good and would pay a market price that was equal to the second highest bid. The subjects were not informed of the dominant strategy of the second-price auction. Each bidder then submitted a private and sealed bid to buy one unit of the good. Step 3: the monitor ranked the bids from highest to lowest. Step 4: the second highest bid set the market-clearing price. Step 5: the monitor posted the market-clearing price as public information. Step 6: the highest bidder purchased one unit of the good at the market price. Step 7: the highest bidder then sold the unit back to the monitor at his or her assigned resale value for that auction. The bidder's profits equaled the difference between his or her resale value and the market-clearing price for that round: profits $=$ resale value - market price. Subjects were informed that they could have negative profits. Step 8: all bidders at or below the market-clearing price did not purchase the good and recorded zero profits. Step 9: the round ended and they returned to Step 1.

For the random $n$ th-price auction, the steps were identical except for the allocation rule. After each player submits a bid and each bid is rank-ordered from highest to lowest, now the monitor selects a random number uniformly distributed between 2 and $k$ bidders. The monitor sells one unit of the good to each of the (n-1) highest bidders at the $n^{\text {th }}$-price. If the monitor, for example, randomly selected $n=6$, the five highest bidders each purchase one unit priced at the sixth-highest bid. Now bidders with low or negative valuation have a nontrivial chance to buy or accept the good since the price is determined randomly. The auction increases the odds that bidding less sincerely leads to negative profits. Each bidder, on- or off-margin, has incentive to bid his private value. 
For the second-price auction, treatments (A), (B), and (C) had three, two, and two sessions, with ten subjects each. For the random nth-price auction, treatments (D), (E), and (F) each had two sessions, ten subjects in each session. Subjects were recruited following standard procedures from undergraduate economic courses.

\section{Results and discussion}

We now present the results for both auctions. Tables 1 and 2 summarize the central tendencies and variances of observed bidding behavior by induced value and treatment for the second-price and random $n$ th-price auctions. ${ }^{12}$ We examine three hypotheses to test aggregate and individual bidding behavior. ${ }^{13,14}$ Consider each in turn, starting with the general question of sincere bidding behavior.

H1: In the pooled sample across the three relevant treatments, subjects bid sincerely in auction $k$ ( $k=$ second-price auction, random nth-price auction).

If all subjects were rational bidders, each bid should equal the induced value, and we would not reject $\mathrm{H} 1$. We test $\mathrm{H} 1$ by nesting it within the general structure

$$
\operatorname{Bid}_{\mathrm{it}}=\alpha+\phi I N_{\mathrm{it}}+u_{\mathrm{i}}+\varphi_{\mathrm{t}}+\varepsilon_{\mathrm{it}}
$$

where $B_{i d}$ it denotes subject i's bid in trial t; $I N_{\text {it }}$ denotes subject i's induced value in trial $\mathrm{t} ; u_{\mathrm{i}}$ represents subject-specific characteristics; $\varphi_{\mathrm{t}}$ represents trial-specific effects, including learning or other trends in bidding behavior; and $\varepsilon_{\mathrm{it}}$ is iid error. In equation (1), data points along a $45^{\circ}$ ray from the origin in $\operatorname{Bid}-I N$ space $\left(\phi=1 ; \alpha=0 ; u_{\mathrm{i}}=\varphi_{\mathrm{t}}=0 \forall \mathrm{t}, \mathrm{i}\right)$ are perfectly demand revealing bids.

For the second-price auction, under the maintained hypothesis that the $u_{\mathrm{i}}$ and the $\varphi_{\mathrm{t}}$ are drawn from a bivariate normal distribution (two-way random effects) the estimated equation is ${ }^{15}$ 


$$
\operatorname{Bid}_{i t}=\underset{(0.29)}{0.13}+\underset{(0.03)}{0.98 I N_{i t}},
$$

The standard errors of the estimates are in parentheses. The regression line is flatter than the perfect-revelation line, with positive intercept and slope below one. Using a Wald test statistic to test the joint hypothesis that $\phi=1$, and $\alpha=0$, however, we cannot reject H1: in aggregate, subjects tended to bid sincerely given both positive and negative values $(\mathrm{W}=3.48 ; \mathrm{p}$-value $=0.18)$.

For the random $n$ th-price auction, the estimated equation is

$$
\operatorname{Bid}_{i t}=-0.18+1.05 I N_{i t}
$$

The standard errors are in parentheses. The regression line is steeper than the perfectrevelation line, with negative intercept and slope greater than one. Using a Wald test statistic to test the joint hypothesis that $\phi=1$, and $\alpha=0$, however, we cannot reject $\mathrm{H} 1$ : in aggregate, subjects tended to bid sincerely given both positive and negative values $(\mathrm{W}=0.95 ; \mathrm{p}$-value $=0.62){ }^{16}$

Our second hypothesis (H2) addresses the issue of whether bidding behavior differs across treatments.

H2: Subjects' bidding behavior with mixed negative and positive induced values does not differ relative to when bidders only have positive induced values in auction $k$ ( $k=$ second-price auction, random nth-price auction).

Theory says that a bidder in a second-price auction in which negative and positive values exist should use the same bidding strategy as if he was in the auction with only positive value bidders. His dominant strategy is to bid his induced value in either case. The testable hypothesis is that bidding behavior is the same for the two positive-negative treatments $(\mathrm{A} \& \mathrm{~B} ; \mathrm{D} \& \mathrm{E})$ relative to the all-positive treatment $(\mathrm{C} ; \mathrm{F})$. 
If bidders use the dominant strategy, each bid should again equal the induced value. To test the hypothesis that bidding behavior is constant across treatments, we estimate the following equation:

$$
B i d_{\text {it }}=\alpha+\phi I N_{\text {it }}+\beta_{1} D_{i t}+\beta_{2} D_{i t} * I N_{\mathrm{it}}+u_{\mathrm{i}}+\varphi_{\mathrm{t}}+\varepsilon_{\mathrm{it}}
$$

where $B_{i d} d_{\mathrm{it}}, I N_{\mathrm{it}}, u_{i}, \varepsilon_{\mathrm{it}}$, and $\varphi_{\mathrm{t}}$ are the same as in equation (1). $D_{i t}$ is a dummy variable that equals one for observations from the positive-negative treatments and zero otherwise, and $D_{i t} * I N_{i t}$ is an interactive variable that equals the subject's induced value in the positivenegative treatment, zero otherwise. The coefficient on $D_{i t}$ shifts the intercept term, while the coefficient on $D_{i t}{ }^{*} I N_{i t}$ changes the slope for the positive-negative treatments. In equation (2), if $\beta_{1}=\beta_{2}=0$, no difference exists in bidding behavior between the positivenegative treatments and the all-positive treatment.

For the second-price auction, based on two-way random effects, the estimated equation is

$$
\text { Bid }_{i t}=\underset{(0.36)}{-0.19}+\underset{(0.07)}{1.02 I N_{i t}}+\underset{(0.38)}{0.40 D_{i t}-0.06 D_{i t}} * I N_{\text {it }}
$$

Standard errors are in parentheses. We see the regression line is slightly flatter and the intercept larger for the positive-negative treatments than for the all-positive treatment. Again using a Wald test statistic to test the joint hypothesis that $\beta_{1}=\beta_{2}=0$, we cannot reject the joint hypothesis $(H 2)$ that the mean of $\beta_{1}=\beta_{2}=0(\mathrm{~W}=1.15$; p-value $=0.56)$. Bidding behavior was not statistically different in the positive-negative treatments than in the all-positive treatment.

For the random nth-price auction, again based on two-way random effects, and estimating equation (2), the estimated equation is

$$
\operatorname{Bid}_{i t}=-0.02+1.00 I N_{i t}+0.02 D_{i t}+0.09 D_{i t} * I N_{\text {it }}
$$



$(0.65)$
(0.12)
$(0.69)$
$(0.14)$

Standard errors are in parenthesis. We see the regression line is slightly steeper and the intercept slightly larger for the positive-negative treatments than for the all-positive treatment. For the all-positive treatment the estimated regression line is near perfect. Again using a Wald test statistic to test the joint hypothesis that $\beta_{1}=\beta_{2}=0$, we cannot reject the joint hypothesis $(H 2)$ that the mean of $\beta_{1}=\beta_{2}=0(\mathrm{~W}=0.79$; $\mathrm{p}$-value $=0.67)$. Bidding behavior was not statistically different in the positive-negative treatments than in the all-positive treatment. ${ }^{17}$

Finally, we consider whether an individual bidder bids differently when confronted with a negative value compared to a positive value. We focus here on bidding behavior in treatments $\mathrm{A} \& \mathrm{~B}$ and $\mathrm{D} \& \mathrm{E}$.

H3: In auction $k$ ( $k$ = second-price auction, random nth-price auction), subjects' bidding behavior in the positive-negative treatments (A\&B or D\&E) does not differ when their induced value is negative relative to when it is positive.

Again, theory predicts that a bidder's behavior should both equal his induced value and be invariant to the distribution of the values. We test the hypothesis by estimating the following equation:

$$
B i d_{\text {it }}=\alpha_{\mathrm{i}}+\phi I N_{\mathrm{it}}+\delta_{1} N E G_{i t}+\delta_{2}\left(N E G_{i t} * I N_{\mathrm{it}}\right)+u_{\mathrm{i}}+\varphi_{\mathrm{t}}+\varepsilon_{\mathrm{it}}
$$

where $\mathrm{Bid}_{\mathrm{it}}, I N_{\mathrm{it}}, u_{\mathrm{i}}, \varepsilon_{\mathrm{it}}$, and $\varphi_{\mathrm{t}}$ are the same as in equation (1) and (2). NEG $G_{i t}$ is a dummy variable, which equals one when bidder $\mathrm{i}$ has a negative value in round $\mathrm{t}$, and equals zero otherwise. $N E G_{i t}$ allows the intercept term to adjust for bids on negative values. $N E G_{i t} * I N_{\text {it }}$ is an interaction term that allows the slope of the regression line to vary between positive and negative values. We test bidder behavior as follows: In equation (3), if $\delta_{1}=\delta_{2}=0$, a bidder's behavior does not differ across positive and negative values. 
For the second-price auction, assuming two-way random effects, the estimated equation is

$$
\begin{aligned}
& B_{i d}=-0.25+1.14 I N_{i t}-0.08 N E G_{i t}-0.31\left(N E G_{i t} * I N_{\text {it }}\right) \\
& \begin{array}{llll}
(0.41) & (0.10) \quad(0.41) & (0.14)
\end{array}
\end{aligned}
$$

Standard errors are in parentheses. We observe the intercept term for the positive values is slightly larger than is the intercept term for negative values, -0.25 versus -0.33 . The slope of the regression line, however, is steeper for positive values relative to negative values, $\phi=1.14$ versus $\left(\phi+\delta_{2}\right)=0.83$. Using a Wald test statistic to test the joint hypothesis that $\delta_{1}=\delta_{2}=0$, we still cannot reject the joint hypothesis $(H 3)(\mathrm{W}=2.78$; pvalue $=0.25)$. Overall, bidding behavior was not statistically different within treatment using standard levels of confidence when subjects had negative and positive induced values. $^{18}$

For the random $n$ th-price auction, the estimated equation is

$$
\operatorname{Bid}_{i t}=\underset{(0.18)}{0.16+1.05 I N_{i t}-1.13 N E G_{i t}-0.24\left(N E G_{i t} * I N_{\mathrm{it}}\right)} \text {. }
$$

Standard errors are in parentheses. We observe that the intercept term for the positive values is much larger than is the intercept term for negative values, 0.16 versus -0.97 . The regression line is steeper for positive values relative to negative values, $\phi=1.05$ versus $\left(\phi+\delta_{2}\right)=0.81$. Using a Wald test statistic to test the joint hypothesis that $\delta_{1}=\delta_{2}$ $=0$, we still cannot reject the joint hypothesis $(H 3)(\mathrm{W}=1.50 ; \mathrm{p}$-value $=0.47) . \quad$ Overall, bidding behavior was not statistically different within treatment when subjects had negative and positive induced values. Moreover, neither estimated coefficient for $N E G_{i t}$ or $\left(N E G_{i t} * I N_{\text {it }}\right)$ are statistically significant providing stronger evidence subjects bidding behavior was not different for positive values relative to negative values. ${ }^{19,20}$ 
We now discuss the implication of these results. One explanation for why no significant difference was found with the joint test for the second-price auction is due to the large variance on the intercept term for the negative treatment. If we step back from the joint hypothesis and evaluate each coefficient estimate separately we find the intercept term is not significantly different from zero, but the slope term, $N E G_{i t} * I N_{\mathrm{it}}$, is different than zero at the 1.5 percent significance level. We see that the average bidder with large positive values overstate their gains, and the average bidder with large negative values overstate their losses. Subjects overbid the positive values by about 14 percent; subjects overbid the negative values by roughly 17 percent $(1.14-0.31=0.83)$. If overbidding pattern transferred to laboratory valuation auctions for controversial products like irradiated meat, the results could cause someone to overrate the extent of public support and to underrate the magnitude of public opposition.

One explanation why negative-value bidders might have overstated their losses in the second-price auction is the disengaged bidder (Shogren et al., 2001). The secondprice auction can fail to engage bidders who fall off the margin of the market-clearing second price. Table 1 shows for most of our negative values, median bids were closer to the negative induced values than the mean bids, which indicate that the average bids were pulled closer to zero by a few negative value bidders who submitted relative large positive bids. If the disengaged bidder thesis explains observed behavior in these treatments, our bidders did not bid randomly above and below the negative induced value, as one could expect; nor did they bid more negatively as if they feared the potential loss. Instead, the average bidder systematically underreported negative values because a few bidders seem to want to be closer to the market-clearing price. Negative 
values themselves do not explain why some low value bidders bid too high; it happens when induced values are all positive as well. The potential risk of any second-price auction is that the off-margin bidders become disengaged, which in our case translated into bidding less negatively than predicted by either rational choice theory or behavioral models of loss aversion.

At first glance, one might conclude the random $n$ th-price auction did better at engaging on-margin and off-margin bidders than the second-price auction. In aggregate subjects in the random $n$ th-price auction bid more sincerely—no difference existed between bidding in the all-positive and the positive-negative treatments. In contrast to the second-price auction, no difference emerged in bidding behavior for positive values relative to negative values. A deeper look into the data and the regression results, however, raises reservations about accepting this conclusion. First, comparing the descriptive statistics for both auction types (tables 1 and 2) shows the distribution of bids around the associated induced value was tighter for the second-price than the random $n$ thprice auction. Table 1 shows the average variance for the second-price auction is 15.07, ranging from 46.33 to 1.48 . Bid variances were about three times higher for the random $n$ th-price auction - the average variance was 41.57 , ranging from 156.52 to 1.48 .

Second, the estimated coefficients' standard errors are smaller for the secondprice auction compared to the same coefficients for the random $n$ th-price auction. Smaller standard errors lead to tighter confidence intervals and more precise tests. ${ }^{21}$ Third, table 3 shows that we omitted 3 percent of the observations (39 of 1200) from the random $n$ th-price auction, and less than 1 percent (10 of 1400) from the second-price auction. More subjects bid erratically more frequently in the random $n$ th-price auction. 
These three points suggests we should combine data across auctions to explore how the two auctions compare in engaging on- and off-margin bidders. We turn to this next.

\section{On-margin and Off-margin bidding}

Similar to Shogren et al. (2001), we examine the effectiveness of the random $n$ th-price auction relative to the second-price auction to engage both on- and off-margin bidders. We separate the induced values into four separate groups: off-margin low values $[\$-5.00$, $\$-2.50]$; off-margin mid values [\$-2.49, \$0.00]; off-margin high values [\$0.01, \$2.50]; and on margin values [ $\$ 2.51, \$ 5.00]$. We segment the induced values into four equal groups to compare the subjects' bidding behavior for small subsamples of values against the entire range of induced values, within and across auction types. Table 4 shows for all four groups the second-price auction had both (a) smaller average and absolute deviation from the induced value, and (b) a tighter variance, which suggests the second-price auction engaged on and off-margin bidders more effectively.

We consider whether this result holds using conditional panel data. Extending the model from equation (1), we estimate the following equation to disentangle the treatment effects on sincere bidding:

$$
\begin{aligned}
& B i d_{i t}=\alpha+\phi_{1} I N_{i t}+\phi_{2}\left(O n * N t h_{i t}\right)+\phi_{3}\left(O{ }^{*} I_{i t} * N t h_{i t}\right)+\phi_{4}\left(h i g h_{i t}\right) \\
& +\phi_{5}\left(h_{i g h}{ }_{i t}{ }^{*} I N_{i t}\right)+\phi_{6}\left(h_{i g h}{ }^{*} N t h_{i t}\right)+\phi_{7}\left(h_{i g h}{ }^{*}{ }^{*} I N_{i t} * N t h_{i t}\right) \\
& +\phi_{8}\left(\operatorname{mid}_{i t}\right)+\phi_{9}\left(\operatorname{mid}_{i t}{ }^{*} I N_{i t}\right)+\phi_{10}\left(\operatorname{mid}_{i t} * N t h_{i t}\right) \\
& +\phi_{11}\left(\operatorname{mid}_{i t}{ }^{*} I_{i t} * N t h_{i t}\right)+\phi_{12}\left(\operatorname{low}_{i t}\right)+\phi_{13}\left(\operatorname{low}_{i t}{ }^{*} I_{i t}\right) \\
& +\phi_{14}\left(\operatorname{low}_{i t} * N t h_{i t}\right)+\phi_{15}\left(\operatorname{low}_{i t} * I N_{i t} * N t h_{i t}\right)+u_{i}+\varepsilon_{i t},
\end{aligned}
$$


where the dependent variable, $B i d_{i t}$, is subject i's bid in trial $\mathrm{t}, u_{i}$ is a subject specific random effect that accounts for systematic differences in bidding patterns and controls for ordering of the experiment types; $I N_{i t}$ is subject i's induced private value in trial $\mathrm{t} ; N t h_{i t}=$ 1 if the subject participated in the random $n$th price auction, 0 otherwise; and $O n_{i t}=1$ for bidder $\mathrm{i}$ in trial $\mathrm{t}$ if his value was in the range $[\$ 5.00, \$ 2.51]$ in trial $\mathrm{t}, 0$ otherwise; and $h_{i g h} h_{i t}=1$ for bidder i in trial $\mathrm{t}$ if his value was in the range $[\$ 2.50, \$ 0.01]$ in trial $\mathrm{t}, 0$ otherwise; and $\mathrm{mid}_{i t}=1$ for bidder $\mathrm{i}$ in trial $\mathrm{t}$ if his value was in the range [\$0.00, \$-2.49] in trial $\mathrm{t}, 0$ otherwise; and $l o w_{i t}=1$ for bidder $\mathrm{i}$ in trial $\mathrm{t}$ if his value was in the range [ $\$$ $2.50, \$-5.00]$ in trial t, 0 otherwise. The remaining variables $I N_{i t}{ }^{*} N t h_{i t}, O N_{i t}{ }^{*} N t h$, $O n_{i t} * I N_{i t} * N t h_{i t}, h_{i g h}{ }_{i t}^{*} I N_{i t}$, high $_{i t} * N t h_{i t}, h_{i g h}{ }_{i t}^{*} I N_{i t} * N t h_{i t}, \operatorname{mid}_{i t} * I N_{i t}, \operatorname{mid}_{i t} * N t h_{i t}$, $\operatorname{mid}_{i t}{ }^{*} I N_{i t}{ }^{*} N t h_{i t}, \operatorname{low}_{i t}{ }^{*} I N_{i t}, \operatorname{low}_{i t} * N t h_{i t}$, and $l o w_{i t}{ }^{*} I N_{i t} * N t h_{i t}$, are interaction terms and allow slope and intercept changes across auction and bidder type (off/on-the-margin bidders).

Table 5 presents the regression results for both the sample with and without outliers. Our discussion focuses on the results with outliers omitted. First consider the slope coefficients. All variables with $I N$ as a component affect the slope of the regression line. Of these slope variables, one is significantly different than zero- the base slope coefficient for the second-price auction, IN. Slope changes in the second-price and random $n$ th-price auction regression lines are perturbations from this base level. All slope coefficients that have $N t h * I N$ relate to the random $n$ th-price auction regression line, while slope coefficients with IN and no Nth correspond to the second-price auction. All other slope coefficients are not significantly different from zero, and adjustments in the slopes are not significantly different from the base slope. This says the slopes of the regression lines are statistically equivalent for the two auctions. 
Examining the intercept terms, all variables that exclude $I N$, indicates the intercepts of the regression lines for both auctions are not statistically different from zero. All estimated coefficients on the intercept terms are insignificant. These results support the hypothesis that no statistical difference exists between the two auctions. Both auctions seemed to perform equally well at engaging on- and off-margin bidders.

Based on the estimated coefficients, table 6 presents the Wald test statistics for the joint hypothesis of zero intercept and slope equal to unity for both on- and off-margin bidders in each auction. We cannot reject the joint hypothesis for off-margin bidders and on-margin bidders in both auctions. This result might have occurred because the standard errors in the random $n$ th-price auction are roughly two to three times larger than in the second-price auction (see table 4). We also examine the p-values on the Wald statistics and see greater odds of rejecting the null for the random $n$ th-price auction relative to the second-price auction for all groupings except low (On: 17 to 59 percent, high: 87 to 100 percent, and mid: 54 to 72 percent). Accompanied with the difference in outliers (22 in treatments D \& E; 8 in treatments A \& B), these results suggest further analysis into the differences in the two auction mechanisms is worth exploring. ${ }^{22}$

Turning to table 3 , we see that 7 of 22 omitted observations were in the low category and 6 of the 7 have relatively large negative bids. One bid, $-10,000$ on a -2.80 induced value, is most likely the driving force behind these results. More subjects in the random $n$ th-price auctions seemed to employ a strategy of bidding extremely low (or large negatives) in rounds in which they had low induced values. One can speculate that these subjects were hoping a high $n$ would be drawn such that the market-clearing price would be an extremely low value creating windfall profits for all the other bidders, e.g., 
all winning bidders get paid, say $\$ 1000$. These strategic bidders could have affected other subjects' bidding behavior by signaling this windfall-bidding through a negative market price such that everyone had a chance to earn windfall profits. Researchers should take caution with the random $n$ th-price auction so exorbitant payoffs are not generated by subjects attempting to game the auction institution. Truncating payoffs would solve this problem but would introduce the complication of not carrying out the payoff procedures described to the subjects.

\section{Conclusion}

Some people who volunteer for laboratory valuation auctions, or a stated preference survey for that matter, can hold negative values for the new product or service being sold on the block (i.e., irradiated meat, GM foods, a ban on snowmobiles in Yellowstone). This article tests whether two alternative Vickrey-style auctions elicited truthful bids across the positive-negative valuation divide, which characterizes consumer reaction to many new products. Our results show that neither the second-price nor the random $n$ thprice auction performed without fault in an induced-value experiment. Aggregate bidding in the second-price auction was precise but biased - highest-positive-value bidders tended to overstate their benefits, whereas lowest-negative-value bidders tended to understate their costs. In contrast, aggregate bidding in the random $n$ th-price auction was demand revealing across all induced values, but it was imprecise - the variance was relatively large and some bidders submitted very negative bids, seemingly strategically.

We are not surprised that the auctions performed less than perfectly—we did not tell subjects about the optimal bidding strategy (e.g., "bid your induced value"), which puts the cognitive burden on them. Evidence reveals hit-and-miss bidding behavior in 
all-positive-induced-values auctions too (see Kagel). What we find surprising is how the average negative-value bidder tended to understate losses in the second-price auction, irrespective of positive or negative induced value, and to overstate losses in the random $n$ th-price auction. What if these results transfer to non-induced laboratory auctions? For Dickinson and Bailey's second-price auction on meat characteristics, our findings suggest their results are an upper bound on consumers' actual valuation of the auction items (as they noted). Though negative bids were relatively rare, actual consumer negative reaction to some types of information they examined would be understated, based on our findings. Caution would be prudent in assessing the magnitude of such laboratory auction bids, though results of such studies can signal the potential retail market share for new products, at least for the case of premium prices (see Shogren et al., 1999). In contrast, had Dickinson and Bailey used a random $n$ th-price auction, their results might have been more demand revealing but more noisy, making it difficult to attach any statistical significance to important changes in bids across individuals auctioned items - a key objective of their study.

We see that the auction mechanism mattered: the second-price auction was precise but biased; the random $n$ th-price auction was unbiased but imprecise. The choice of auction can attenuate or exaggerate subjects' negative reactions to a new good. An outside observer using such laboratory data should note the risk of underestimating the negative reaction to new goods in the marketplace (e.g., consumer picketing or boycotts). More research exploring the robustness of our findings to alternative auctions, real commodities, and assessing their external validity in retail markets seems worthwhile. 


\section{Footnotes}

1. See Bruhn, Caswell and Padberg, Food and Water, Inc., Fox et al. (1995, 2002), Gates, and Greenpeace International.

2. See Aquino and Falk's survey and retail study on "wolf-friendly" beef in New Mexico.

3. See for example Alfnes and Rickertsen; Buhr et al.; Fox et al. (1994, 1995, 1998, 2002); Hoffman et al., Huffman et al., Lusk et al.; Roosen et al.; and Shogren et al. (1999).

4. As is standard experimental protocol, researchers try to avoid questions of selfselection by not telling potential subjects what the experiment is about or what products will be sold. People are asked to participate in a "consumer food experiment" in return for a participation fee to cover their opportunity cost.

5. The question of what to do with negative values has also concerned researchers who use contingent valuation surveys to elicit values for environmental protection. The concern is that some respondents who answer the survey valuation questions might have negative values for a change in environmental conditions but are prevented from expressing these concerns in their willingness to pay response (Bohara, Kerkvliet, and Berrens.).

6. Experimental evidence suggests the second price auction produces an efficient outcome in the aggregate; individual bidders, however, do not always bid sincerely (see Kagel; Knetsch, Tang, and Thaler).

7. By prescreening, people who would bid negative values for the pst growth hormone pork (sandwich) were actually given the pst pork sandwich as their endowed sandwich 
and asked to bid on their willingness to pay to exchange that sandwich with a non-pst pork sandwich.

8. Other studies include Bohara, Kerkvliet, and Berrens, and Macmillan, Duff, and Elston. Regardless of whether the focus is on allowing negative responses to willingnessto-pay questions or substituting willingness-to-pay for willingness-to-accept questions, the core issue is that different people can have positive or negative values for the same private or public good.

9. Dickinson and Bailey design a valuation experiment that explicitly allowed for negative bids. They examine consumer bidding behavior on meat characteristics, e.g., ability to trace retail meat back to the farm or animal; knowing the meat was produced without growth hormones or the animal was humanely treated, and extra meat safety assurances.

10. Also, in terms of the WTP-WTA gap in valuing safer food, for instance, a WTP elicitation frames the product as a "good"- people bid their WTP for more food safety (see Shogren et al., 1994). In eliciting WTA values, the identical product is framed as a "bad"- people bid their WTA for less food safety.

11. Experimental instructions are available on request from the authors.

12. An open question is how to treat outlying responses in auction experiments. Belsley, Kuh, and Welsch address this question by considering subsets of influential data. One issue is lack of clarity on the separating line between data to be excluded and included. A test to determine the cutoff point could be a joint test that embodies a trade-off between the degree of influence an additional data point has on parameters and the likelihood of removing a "valid" observation. Otherwise, one has two options: Eliminate no data or 
the intuitive approach of eliminating outliers that are bad data "to the best of the user's knowledge." We follow both approaches by considering all the data and by excluding responses with an absolute difference between bid and value exceeding $\$ 50.00$.

13. Appendix A, available on request from the authors, shows the results when all outliers are included do not differ from the results obtained from the sample when outliers are omitted. The main differences is the variances of the estimated coefficients are larger relative to the coefficient value when all observations are considered, causing the estimated coefficients to have a larger confidence interval around zero and in turn a higher probability of being insignificant. This observation is confirmed on the regression of $\mathrm{H} 3$ in which no estimated coefficients are statistically different from zero.

14. In Appendix B (available on request) we redo the statistics for the random $n$ th-price auction to compare the results between the sample in which outlier observations are omitted and the sample in which no observations are omitted. The results obtained from the sample when outliers are included do not differ from the results obtained from the sample when outliers are omitted. We again see the variances of the estimated coefficients are larger relative to the coefficient value, causing the estimated coefficients to have a larger confidence interval around zero and in turn a higher probability of being insignificant. This observation is confirmed in each regression because no estimated coefficients are statistically different from zero.

15. Given the LM statistic and the Hausman test both suggest the random effects model is appropriate for our data, we focus on estimates from the more efficient error components model in all of the regression results reported. Results from two-way covariance models are qualitatively similar in each case. 
16. We test for structural differences between the estimates of the coefficients for the two samples, the second-price auction and the random $n$ th-price auction. The typical approach is to use a Chow test, which assumes the variances of the disturbance terms are the same across the entire sample (Greene). But in examining the sum-squared errors for both regressions, the two sub-samples appear to have unequal disturbance term variances. We test the null hypothesis that the variances of the disturbance terms are identical using the Goldfeld-Quandt test. We reject the null hypothesis at the 1 percent level $(\mathrm{F}(1157$, $1386)=3.104 ; p$-value $<0.0001)$. Because the variance terms differ across samples the Chow test can overestimate the test statistic (Schmidt and Sickles). A valid test for large samples is the Wald test for structural change which is unaffected by differences in subsample disturbance term variances (Greene). We cannot reject the null hypothesis that the estimated coefficients are equal $\left(\chi_{4}^{2}=2.02 ; p-\right.$ value $\left.=0.36\right)$. Bidding behavior does not differ between the two auction types.

17. Again we test for structural differences between the estimates of the coefficients for the two samples. Again the two sub-samples have unequal disturbance term variances, so we test the null that the variances of the disturbance terms are the same using the Goldfeld-Quandt test. We reject the null at the 1 percent level $(F(1157,1386)=3.104$; pvalue $<0.0001)$. Using the Wald test for structural change, we cannot reject the null hypothesis that the estimated coefficients are equal $\left(\chi_{4}^{2}=2.92 ; p-\right.$ value $\left.=0.57\right)$. Again bidding behavior was similar in the two auctions.

18. In Appendix $C$ (available on request), we redo the statistics to compare the results for $\mathrm{H} 2$ and $\mathrm{H} 3$ when a treatment dummy and a treatment interactive variable are added to show the differences in slope and intercept coefficients for each treatment. We compared 
these results to those obtained in the text. Looking at the induced values for each treatment, we observe in treatment A subjects possessed negative induced values in half the rounds, while in treatment B negative values occurred less than a third of the time. We cannot say that increased exposure to negative values increases the propensity for subjects to bid negative values more sincerely. In contrast, it implies the opposite. One explanation is the disengaged bidder. As subjects face negative values more frequently, and if the market price is always positive, they now see they have little chance to win the good given a negative value and are therefore less likely to bid sincerely.

19. Using the Goldfeld-Quandt test we reject the null that the variances of the disturbance terms are the same at the 1 percent level $(F(774,988)=3.84$; p-value $<0.0001)$. Using the Wald test for structural change, we cannot reject the null the estimated coefficients are equal $\left(\chi_{4}^{2}=3.64 ; p-\right.$ value $\left.=0.46\right)$.

20. In Appendix D (available on request), we redo the statistics to compare the results for $\mathrm{H} 2$ and $\mathrm{H} 3$ when a treatment dummy and a treatment interactive variable is added to show the different slope and intercept coefficients for each treatment. Comparing these results to those in the text, we see the regression results for $\mathrm{H} 2$ with a treatment intercept variable and interactive slope term lead to the same conclusions. Bidding did not differ across all-positive and positive-negative treatments even when we control for treatment effects. For H3, individual treatment regressions gave conflicting results: in treatment D subjects bidding behavior did not differ between positive and negative values; in treatment $\mathrm{E}$ subjects behavior differed between positive and negative values. A Wald test for structural change between two samples, however, indicated that bidding behavior did not differ between treatments $\mathrm{D}$ and $\mathrm{E}$, and we can treat the two samples as one. 
21. While recognizing the caveats, the $\mathrm{R}^{2} \mathrm{~s}$ are nearly twice as large for the second-price auction regressions relative to the random $n$ th-price auction regressions suggesting that the model fits the data better.

22. We consider the sample with all observations. Assuming two-way random effects we estimate equation (4). Column two of table 5 shows the results. The results from the entire sample differ substantially from the omitted observation sample. Now the coefficient estimates on Nth*Low and Nth*Low*IN are significant. All other coefficients are not statistically different than zero. Based on these estimated coefficients, table 6 presents the Wald test statistics for the joint hypothesis of zero intercept and slope equal to 1 for both on- and off-margin bidders in each auction for the entire sample. We cannot reject the joint hypothesis for on-margin and off-margin high and off-margin mid bidders in both auctions. For off-margin low bidders we cannot reject the null hypothesis in the second-price auction. We reject the joint hypothesis for off-margin low bidders in the random $n$ th-price auction at the 1 percent significance level. Observed behavior in the random $n$ th-price auction for low values deviated from theoretical predictions. 


\section{References}

Alfnes, F. and K. Rickertsen. "European Consumers Willingness to pay for U.S. Beef in Experimental Auction Markets." American Journal of Agricultural Economics, in press.

Aquino, H. and C. Falk. "A Case Study in the Marketing of "Wolf-Friendly" Beef." Review of Agricultural Economics 23(2001): 524-37.

Belsley, D., E. Kuh, and R. Welsch. Regression Diagnostics: Identifying Influential Data and Sources of Collinearity. New York: John Wiley \& Sons, 1980.

Bohara, A., J. Kerkvliet, and R. Berrens. "Addressing Negative Willingness to Pay in Dichotomous Choice Contingent Valuation." Environmental and Resource Economics 20(2001): 173-95.

Bruhn, C. "Consumer Attitudes and Market Response to Irradiated Food." Journal of Food Protection 58(1995): 175-81.

Buhr, B., D. Hayes, J. Shogren, and J. Kliebenstein. "Valuing Ambiguity: The Case of Genetically Engineered Growth Enhancers." Journal of Agricultural and Resource Economics 18(1993): 175-84.

Camerer, C. "Individual Decision Making." Handbook of Experimental Economics. J. Kagel and A. Roth, eds. pp. 587-703. Princeton NJ: Princeton University Press, 1995.

Caswell, J. and D. Padberg. "Toward a More Comprehensive Theory of Food Labels." American Journal of Agricultural Economics 74 (1992):460-67.

Clinch, J., and A. Murphy. "Modelling Winners and Losers in Contingent Valuation of Public Goods: Appropriate Measures and Econometric Analysis." Economic Journal 111(2001): 420-43.

Diamond, P., and J. Hausman. "Contingent Valuation: Is Some Number Better than No Number?” Journal of Economic Perspectives 8(1994): 45-64.

Dickinson, D. and D. Bailey. "Meat Traceability: Are U.S. Consumers Willing to Pay for It?” Journal of Agricultural and Resource Economics 27(2002): 348-64.

Food and Water, Incorporated (undated). Answers to Questions about Food Irradiation. Marshfield, Vermont.

Fox, J., D. Hayes, J. Kliebenstein, and J. Shogren. "Consumer Acceptability of Milk from Cows Treated with Bovine Somatotropin.” Journal of Diary Science 77(1994): 70307. 
Fox, J., B. Buhr, J. Shogren, J. Kliebenstein, and D. Hayes. "A Comparison of Preferences for Pork Sandwiches Produced from Animals with and without Somatotropin Administration.” Journal of Animal Science 73(1995): 1048-54.

Fox, J., J. Shogren, D. Hayes, and J. Kliebenstein. "CVM-X: Calibrating Contingent Values with Experimental Auction Markets." American Journal of Agricultural Economics 80(1998): 455-65.

Fox, J., D. Hayes, and J. Shogren. "Consumer Preferences for Food Irradiation: How Favorable and Unfavorable Descriptions affect Preferences for Irradiated Pork in Experimental Auctions." Journal of Risk and Uncertainty 24(2002): 75-95.

Franciosi, R., R. M. Isaac, D. Pingry, and S. Reynolds. "An Experimental Investigation of the Hahn-Noll Revenue Neutral Auction for Emissions Licenses." Journal of Environmental Economics and Management 24(1993): 1-24.

Gates, B.. "Will Frankenfood Feed the World?" Time. Visions of the $21^{\text {st }}$ Century. Time.com, www.time.com/time/reports/v21/tech/mag food.html, 2001.

Greene, W. Econometric Analysis. Upper Saddle River NJ: Prentice Hall, 1997.

Greenpeace International. “We Want Natural Food!” www.greenpeace.org/ geneng/, March 2001

Goldfeld, S. and R. Quandt. "Some Tests for Homoscedasticity." Journal of the American Statistical Association 60(1965): 539-47.

Hanemann, W. M. "Valuing the Environment through Contingent Valuation." Journal of Economic Perspectives 8(1994): 19-44.

Hausman, J. “Specification Tests in Econometrics.” Econometrica 46(1978): 1251-71.

Hoffman, E., D. Menkhaus, D. Chakravarti, R. Field, and G. Whipple. "Using Laboratory Experimental Auctions in Marketing Research: A Case Study of New Packaging for Fresh Beef." Marketing Science 12(1993): 318-38.

Huffman, W., J. Shogren, M. Rousu, and A. Tegene. "The Value to Consumers of Genetically Modified Food Labels in a Market with Diverse Information: Evidence from Experimental Auctions.” Dept. Econ., Iowa State University, 2003.

Kagel, J. “Auctions: A Survey of Experimental Research.” Handbook of Experimental Economics. J. Kagel and A. Roth, eds. pp. 501-85. Princeton NJ: Princeton University Press, 1995.

Kahneman, D. and A. Tversky. "Prospect Theory: An Analysis of Decision under Risk." Econometrica 47(1979): 263-91. 
Kahneman, D. and A. Tversky, eds. Choice, Values, and Frames. New York: Cambridge University Press, 2000.

Knetsch, J., F.-F. Tang, and R. Thaler. "The Endowment Effect and Repeated Market Trials: Is the Vickrey Auction Demand Revealing?" Experimental Economics 4(2001): 257-69.

Lusk, J., M. Daniel, D. Mark, and C. Lusk. "Alternative Calibration and Auction Institutions for Predicting Consumer Willingness to Pay of Nongenetically Modified Corn Chips." Journal of Agricultural and Resource Economics 26(2001): 40-57.

Macmillan, D., E. Duff, and D. Elston. "Modeling the Non-Market Environmental Costs and Benefits of Biodiversity Projects Using Contingent Valuation Data." Environmental and Resource Economics 18(2001): 391-410.

Roosen, J., J. Fox, D. Hennessy, and A. Schreiber. "Consumers' Valuation of Insecticide Use Restrictions: An Application to Apples." Journal of Agricultural and Resource Economics 23 (1998): 367-84.

Schmidt, P. and R. Sickles. "Some Further Evidence on the use of Chow Tests under Heteroscedasticity.” Econometrica 45(1977): 1293-98.

Shogren, J. "Experimental Methods and Valuation." Handbook of Environmental Economics. K.-G. Mäler and J. Vincent, eds. Amsterdam: North Holland, in press.

Shogren, J., J. Fox, D. Hayes and J. Roosen. "Observed Choices for Food Safety in Retail, Survey, and Auction Markets." American Journal of Agricultural Economics 81(1999): 1192-99.

Shogren, J., M. Margolis, C. Koo, and J. List. "A Random nth-price Auction." Journal of Economic Behavior and Organization 46(2001): 409-21.

Shogren, J., S. Y. Shin, D. Hayes, and J. Kliebenstein. "Resolving Differences in Willingness to Pay and Willingness to Accept." American Economic Review 84(1994): 255-70.

Smith V.L. "Microeconomic Systems as an Experimental Science." American Economic Review 72(1982): 923-55.

Vickrey, W. "Counterspeculation, Auctions and Competitive Sealed Tenders." Journal of Finance 16(1961): 8-37.

Viscusi, W. K. "Alarmist Decisions with Divergent Risk Information.” Economic Journal 107(1997): 1657-70. 
Table 1. Summary Statistics on Bidding Behavior by Induced Value \&

Treatment-Excluding Outliers in which $\mid$ Value-Bid $\mid \geq \mathbf{5 0}$

Sample Properties

\begin{tabular}{|c|c|c|c|c|c|c|c|c|c|}
\hline \multirow{3}{*}{$\begin{array}{l}\text { Induced } \\
\text { Value }\end{array}$} & \multirow{2}{*}{\multicolumn{3}{|c|}{$\begin{array}{l}\text { Treatment A } \\
5 \mathrm{Neg}-5 \text { Pos }\end{array}$}} & \multirow{2}{*}{\multicolumn{3}{|c|}{$\begin{array}{l}\text { Treatment B } \\
3 \mathrm{Neg}-7 \text { Pos }\end{array}$}} & \multirow{2}{*}{\multicolumn{3}{|c|}{$\begin{array}{l}\text { Treatment C } \\
\text { All Positive }\end{array}$}} \\
\hline & & & & & & & & & \\
\hline & $\bar{X}$ & Med & $\sigma^{2}$ & $\bar{X}$ & Med & $\sigma^{2}$ & $\bar{X}$ & Med & $\sigma^{2}$ \\
\hline 8.9 & & & & & & & 9.08 & 8.87 & 3.68 \\
\hline 7.9 & & & & & & & 7.30 & 7.90 & 13.29 \\
\hline 7.6 & & & & & & & 7.68 & 7.60 & 21.50 \\
\hline 6.3 & & & & & & & 5.71 & 6.30 & 34.83 \\
\hline 5.2 & & & & & & & 5.96 & 5.20 & 10.66 \\
\hline 4.4 & & & & 5.04 & 4.40 & 9.92 & & & \\
\hline 4.0 & & & & & & & 4.27 & 3.99 & 14.24 \\
\hline 3.9 & 4.35 & 3.90 & 9.57 & & & & & & \\
\hline 3.5 & & & & & & & 3.38 & 3.50 & 9.75 \\
\hline 3.2 & & & & 2.95 & 3.20 & 28.28 & & & \\
\hline 3.1 & & & & 3.62 & 3.10 & 20.56 & & & \\
\hline 2.9 & 3.06 & 2.90 & 2.68 & 2.89 & 2.9 & 21.05 & & & \\
\hline 2.6 & 2.37 & 2.60 & 1.48 & & & & & & \\
\hline 2.2 & & & & & & & 2.10 & 2.20 & 9.48 \\
\hline 1.4 & & & & 1.40 & 1.40 & 46.33 & & & \\
\hline 1.3 & 1.27 & 1.30 & 2.74 & 1.48 & 1.30 & 11.51 & & & \\
\hline 1.1 & & & & & & & 0.57 & 1.10 & 18.58 \\
\hline 0.8 & & & & 0.61 & 0.80 & 11.99 & & & \\
\hline 0.3 & & & & & & & 0.06 & 0.29 & 21.71 \\
\hline 0.2 & 0.21 & 0.19 & 4.40 & & & & & & \\
\hline-1.0 & -1.25 & -1.00 & 4.99 & & & & & & \\
\hline $\begin{array}{l}-1.3 \\
\end{array}$ & & & & -1.80 & \begin{tabular}{|l|}
-1.3 \\
\end{tabular} & 12.68 & & & \\
\hline
\end{tabular}




\begin{tabular}{|c|c|c|c|c|c|c|c|}
\hline-1.5 & -0.87 & -1.50 & 3.92 & & & & \\
\hline-2.8 & -2.18 & -2.80 & 3.57 & & & & \\
\hline-3.9 & -3.07 & -3.9 & 8.83 & & & & \\
\hline-4.4 & & & & -4.02 & -4.40 & 43.41 & \\
\hline-4.7 & -3.76 & -4.7 & 11.93 & & & & \\
\hline \multirow[t]{2}{*}{-4.8} & & & & -5.13 & -4.80 & 34.49 & \\
\hline & & $\mathrm{N}=60$ & & & $\mathrm{~N}=40$ & & $\mathrm{~N}=40$ \\
\hline
\end{tabular}

Note: each subject faced each value twice.

Bids that were either greater than the induced value by $\$ 50$, or less than the induced value by $-\$ 50$ were excluded.

$\mathrm{N}$ is the number of observations per induced value. 
Table 2. Summary Statistics on Bidding Behavior by Induced Value \& Treatment - Random $n$th -Price auction, Excluding Outliers in which $\mid$ Value-Bid $\mid \geq$ 50.

Sample Properties

\begin{tabular}{|c|c|c|c|c|c|c|c|c|c|}
\hline \multirow{3}{*}{$\begin{array}{l}\text { Induced } \\
\text { Value }\end{array}$} & \multirow{2}{*}{\multicolumn{3}{|c|}{$\begin{array}{l}\text { Treatment D } \\
5 \text { Neg - } 5 \text { Pos }\end{array}$}} & \multirow{2}{*}{\multicolumn{3}{|c|}{$\begin{array}{l}\text { Treatment E } \\
3 \text { Neg - } 7 \text { Pos }\end{array}$}} & \multirow{2}{*}{\multicolumn{3}{|c|}{$\begin{array}{l}\text { Treatment F } \\
\text { All Positive }\end{array}$}} \\
\hline & & & & & & & & & \\
\hline & $\bar{X}$ & \multirow[t]{2}{*}{ Med } & \multirow[t]{2}{*}{$\sigma^{2}$} & \multirow[t]{2}{*}{$\bar{X}$} & \multirow[t]{2}{*}{ Med } & \multirow[t]{2}{*}{$\sigma^{2}$} & \multirow{2}{*}{$\begin{array}{c}\bar{X} \\
9.17\end{array}$} & \multirow{2}{*}{$\begin{array}{l}\text { Med } \\
8.89\end{array}$} & \multirow{2}{*}{$\begin{array}{l}\sigma^{2} \\
8.87\end{array}$} \\
\hline 8.9 & & & & & & & & & \\
\hline 7.9 & & & & & & & 8.51 & 7.89 & 69.21 \\
\hline 7.6 & & & & & & & 7.63 & 7.55 & 31.78 \\
\hline 6.3 & & & & & & & 5.81 & 6.29 & 16.16 \\
\hline 5.2 & & & & & & & 4.99 & 5.19 & 33.35 \\
\hline 4.4 & & & & 7.72 & 4.39 & 148.49 & & & \\
\hline 4.0 & & & & & & & 3.96 & 4.00 & 1.48 \\
\hline 3.9 & 2.15 & 3.75 & 70.30 & & & & & & \\
\hline 3.5 & & & & & & & 2.33 & 3.49 & 26.01 \\
\hline 3.2 & & & & 2.77 & 3.19 & 10.05 & & & \\
\hline 3.1 & & & & 3.12 & 3.09 & 13.26 & & & \\
\hline 2.9 & 3.29 & 2.90 & 39.64 & 2.95 & 2.89 & 3.71 & & & \\
\hline 2.6 & 3.10 & 2.53 & 68.41 & & & & & & \\
\hline 2.2 & & & & & & & 2.42 & 2.19 & 13.42 \\
\hline 1.4 & & & & 1.91 & 1.39 & 13.50 & & & \\
\hline 1.3 & 1.05 & 1.20 & 8.49 & 1.56 & 1.30 & 4.96 & & & \\
\hline 1.1 & & & & & & & 1.72 & 1.00 & 22.83 \\
\hline 0.8 & & & & 0.86 & 0.79 & 31.78 & & & \\
\hline 0.3 & & & & & & & 0.47 & 0.29 & 4.14 \\
\hline 0.2 & 1.39 & 0.20 & 37.10 & & & & & & \\
\hline-1.0 & -2.18 & -1.00 & 40.41 & & & & & & \\
\hline
\end{tabular}




\begin{tabular}{|c|c|c|c|c|c|c|c|}
\hline-1.3 & & & & -2.37 & -1.31 & 28.37 & \\
\hline-1.5 & -1.93 & -1.00 & 104.84 & & & & \\
\hline-2.8 & -4.38 & -2.80 & 90.70 & & & & \\
\hline-3.9 & -1.99 & -3.9 & 36.69 & & & & \\
\hline-4.4 & & & & -5.51 & -4.41 & 75.61 & \\
\hline-4.7 & -6.76 & -4.70 & 156.52 & & & & \\
\hline-4.8 & & & & -2.96 & -4.81 & 36.95 & \\
\hline & & $\mathrm{N}=40$ & & & $\mathrm{~N}=40$ & & $\mathrm{~N}=40$ \\
\hline
\end{tabular}

Note: each subject faced each value twice.

Bids that were either greater than the induced value by $\$ 50$, or less than the induced value by $-\$ 50$ were excluded. 
Table 3. Omitted Observations When $\mid$ Value-Bid $\mid \geq \mathbf{5 0}$.

\begin{tabular}{|c|c|c|c|c|c|c|c|c|c|}
\hline Treatment & Round & Player & Value & Bid & Treatment & Round & Player & Value & Bid \\
\hline B & 8 & 41 & -4.40 & -1000.00 & $\mathrm{D}$ & 10 & 86 & 0.20 & -1000.00 \\
\hline $\mathrm{B}$ & 8 & 43 & 4.40 & -50.00 & $\mathrm{D}$ & 7 & 86 & 2.90 & 100.00 \\
\hline $\mathrm{B}$ & 12 & 43 & 2.90 & -50.00 & $\mathrm{D}$ & 20 & 88 & -3.90 & -150.00 \\
\hline $\mathrm{B}$ & 13 & 43 & 1.40 & -500.00 & $\mathrm{D}$ & 20 & 101 & 1.30 & -100.00 \\
\hline B & 14 & 43 & -1.30 & -200.00 & E & 3 & 101 & -4.80 & -75.00 \\
\hline $\mathrm{B}$ & 10 & 43 & -4.40 & -200.00 & E & 1 & 101 & -4.40 & -200.00 \\
\hline $\mathrm{B}$ & 9 & 43 & 0.80 & -100.00 & E & 2 & 108 & -4.80 & 50.00 \\
\hline $\mathrm{B}$ & 3 & 48 & -1.30 & 100.00 & F & 9 & 115 & 0.30 & -100.00 \\
\hline $\mathrm{C}$ & 4 & 59 & 7.60 & -150.00 & $\mathrm{~F}$ & 8 & 115 & 4.00 & -75.00 \\
\hline $\mathrm{C}$ & 8 & 62 & 2.20 & -150.00 & $\mathrm{~F}$ & 11 & 115 & 7.60 & -1000.00 \\
\hline $\mathrm{D}$ & 17 & 71 & -4.70 & -100.00 & $\mathrm{~F}$ & 3 & 125 & 0.30 & -100.00 \\
\hline $\mathrm{D}$ & 20 & 71 & -2.80 & -10000.00 & $\mathrm{~F}$ & 9 & 125 & 0.30 & -50.00 \\
\hline $\mathrm{D}$ & 9 & 71 & 1.30 & -50.00 & $\mathrm{~F}$ & 12 & 125 & 1.10 & -74.00 \\
\hline $\mathrm{D}$ & 16 & 71 & 2.60 & -100.00 & $\mathrm{~F}$ & 6 & 125 & 2.20 & -1000000.00 \\
\hline $\mathrm{D}$ & 6 & 72 & -1.00 & 105.00 & $\mathrm{~F}$ & 5 & 125 & 3.50 & -1000000.00 \\
\hline $\mathrm{D}$ & 3 & 73 & -2.8 & 500.00 & $\mathrm{~F}$ & 8 & 125 & 4.00 & -94.00 \\
\hline $\mathrm{D}$ & 4 & 73 & 3.90 & 400.00 & $\mathrm{~F}$ & 4 & 125 & 6.30 & -100000.00 \\
\hline $\mathrm{D}$ & 1 & 73 & -1.00 & 200.00 & $\mathrm{~F}$ & 2 & 125 & 6.30 & -1000.00 \\
\hline $\mathrm{D}$ & 2 & 73 & -1.00 & 150.00 & F & 11 & 125 & 7.60 & -94.00 \\
\hline $\mathrm{D}$ & 3 & 74 & 1.30 & 200.00 & F & 10 & 125 & 7.90 & -94.00 \\
\hline $\mathrm{D}$ & 6 & 80 & -1.50 & -721.00 & $\mathrm{~F}$ & 7 & 125 & 8.90 & -1000000.00 \\
\hline $\mathrm{D}$ & 12 & 80 & -1.00 & -720.00 & $\mathrm{~F}$ & 1 & 125 & 8.90 & 1000.00 \\
\hline $\mathrm{D}$ & 3 & 80 & 0.20 & 217.62 & F & 3 & 128 & 1.1 & -50.00 \\
\hline $\mathrm{D}$ & 11 & 80 & -2.80 & -167.50 & F & 4 & 128 & 7.60 & 100.00 \\
\hline D & 2 & 80 & 2.60 & 150.00 & & & & & \\
\hline
\end{tabular}




$\begin{array}{ccc}\begin{array}{c}\text { Second-Price } \\ \text { Auction }\end{array} & \begin{array}{c}\text { Random } \\ n \text { th-Price } \\ \text { Auction }\end{array} & \text { Aggregate } \\ & & \\ & \end{array}$

\begin{tabular}{lccc}
\hline On-margin & $0.18(3.41)$ & $0.30(7.16)$ & $0.23(5.43)$ \\
& $1.50(3.09)$ & $3.02(6.50)$ & $2.19(4.97)$ \\
& $\mathrm{N}=338$ & $\mathrm{~N}=276$ & $\mathrm{~N}=614$ \\
Off-margin high & & & \\
& $-0.01(3.61)$ & $0.36(4.36)$ & $0.16(3.96)$ \\
& $1.51(3.28)$ & $1.98(3.90)$ & $1.72(3.57)$ \\
& $\mathrm{N}=238$ & $\mathrm{~N}=195$ & $\mathrm{~N}=433$ \\
Off-margin mid & & & \\
& $0.03(2.56)$ & $-0.89(7.56)$ & $-0.36(5.29)$ \\
& $1.39(2.15)$ & $4.31(6.63)$ & $2.37(4.74)$ \\
& $\mathrm{N}=158$ & $\mathrm{~N}=115$ & $\mathrm{~N}=273$ \\
& & & \\
Off-margin low & $0.56(4.15)$ & $-0.20(8.98)$ & $0.24(6.66)$ \\
& $2.27(3.52)$ & $3.72(7.88)$ & $3.14(5.88)$ \\
& $\mathrm{N}=258$ & $\mathrm{~N}=192$ & $\mathrm{~N}=450$ \\
& & & \\
Aggregate & $0.21(3.56)$ & $0.02(7.16)$ & $0.12(5.44)$ \\
& $1.69(3.14)$ & $3.18(6.42)$ & $2.34(4.91)$ \\
& $\mathrm{N}=992$ & $\mathrm{~N}=778$ & $\mathrm{~N}=1770$ \\
\hline On-margin is the set of Values $\$ 250$ to $\$ 5.00]$ & &
\end{tabular}

On-margin is the set of Values [ $\$ 2.50$ to $\$ 5.00]$.

Off-margin high is the set of Values [ $\$ 0.00$ to $\$ 2.50]$.

Off-margin mid is the set of Values [ $\$-2.50$ to $\$ 0.00]$.

Off-margin low is the set of Values [ $\$-5.00$ to $\$-2.50]$.

Each cell gives mean deviations on the top line with S.D. in parenthesis, and then the mean absolute deviations on the bottom line with S.D. in parenthesis. 
Table 5. GLS (Random Effects) Estimation Results-On Margin, Off Margin Bidders

\begin{tabular}{|c|c|c|}
\hline Variable & Omitted Observation Sample & Entire sample \\
\hline \multirow[t]{2}{*}{ CONSTANT } & -1.19 & -0.29 \\
\hline & $(1.68)$ & $(73.27)$ \\
\hline \multirow[t]{2}{*}{$I N$} & $1.42^{* * *}$ & 1.04 \\
\hline & $(0.51)$ & $(22.13)$ \\
\hline \multirow[t]{2}{*}{ High } & 1.14 & 1.31 \\
\hline & $(1.85)$ & $(81.00)$ \\
\hline \multirow[t]{2}{*}{ Mid } & -0.80 & -1.71 \\
\hline & $(3.03)$ & $(133.27)$ \\
\hline \multirow[t]{2}{*}{ Low } & 2.32 & 8.37 \\
\hline & $(2.49)$ & $(109.19)$ \\
\hline \multirow[t]{2}{*}{$H i g h * I N$} & -0.37 & -3.73 \\
\hline & $(0.89)$ & $(39.11)$ \\
\hline \multirow[t]{2}{*}{$M i{ }^{*} I N$} & -2.02 & -1.16 \\
\hline & $(2.04)$ & $(89.67)$ \\
\hline \multirow[t]{2}{*}{ Low*IN } & -0.28 & 2.95 \\
\hline & $(0.68)$ & $(29.61)$ \\
\hline \multirow[t]{2}{*}{ Nth*On } & -1.51 & -6.39 \\
\hline & $(2.51)$ & $(109.22)$ \\
\hline \multirow[t]{2}{*}{ Nth*High } & 1.14 & -19.33 \\
\hline & $(1.24)$ & $(53.67)$ \\
\hline \multirow[t]{2}{*}{ Nth*Mid } & -0.70 & 16.05 \\
\hline & $(4.11)$ & $(176.02)$ \\
\hline \multirow[t]{2}{*}{ Nth*Low } & -3.38 & $-549.55^{* * *}$ \\
\hline & $(2.93)$ & $(126.25)$ \\
\hline \multirow[t]{2}{*}{$N t h * O n * I N$} & 0.50 & 2.66 \\
\hline & $(0.75)$ & $(32.84)$ \\
\hline \multirow[t]{2}{*}{ Nth $* H i g h * I N$} & -0.77 & 18.66 \\
\hline & $(1.14)$ & $(49.39)$ \\
\hline \multirow[t]{2}{*}{$N t h * M i d * I N$} & 0.18 & 19.34 \\
\hline & $(3.19)$ & $(137.26)$ \\
\hline \multirow[t]{2}{*}{ Nth*Low*IN } & -0.64 & $-122.10^{* * *}$ \\
\hline & $(0.71)$ & $(30.38)$ \\
\hline $\mathrm{R}^{2}$ & 0.24 & 0.02 \\
\hline $\mathrm{N}$ & 1770 & 1800 \\
\hline \multicolumn{3}{|c|}{ Standard errors are in parentheses } \\
\hline
\end{tabular}


Table 6. Tests of Joint Hypothesis of Zero Intercept, Unit Slope

Omitted Observation Sample

Random $n$ th-Price Auction

Second-Price Auction

On-margin

$\chi_{2}^{2}=3.57, p$-value $=0.17$

$\chi_{2}^{2}=1.04, p$-value $=0.59$

Off-margin High

$\chi_{2}^{2}=0.28, p$-value $=0.87$

$\chi_{2}^{2}=0.01, p$-value $=1.00$

Off-margin Mid

$\chi_{2}^{2}=1.22, p$-value $=0.54$

$\chi_{2}^{2}=0.66, p$-value $=0.72$

Off-margin Low

$\chi_{2}^{2}=1.94, p$-value $=0.38$

$\chi_{2}^{2}=2.83, p$-value $=0.24$

\section{Entire Sample}

On-margin

$\chi_{2}^{2}=0.04, p$-value $=0.98$

$\chi_{2}^{2}=0.00, p$-value $=1.00$

\section{Off-margin High}

$\chi_{2}^{2}=0.13, p$-value $=0.94$

$\chi_{2}^{2}=0.04, p$-value $=0.98$

Off-margin Mid

$\chi_{2}^{2}=0.02, p$-value $=0.99$

$\chi_{2}^{2}=0.00, p$-value $=1.00$

Off-margin Low

$$
\chi_{2}^{2}=17.83^{* *}, p \text {-value }=0.0001 \quad \chi_{2}^{2}=0.10, p \text {-value }=0.95
$$

\footnotetext{
On-margin is the set of Values [ $\$ 2.50$ to $\$ 5.00]$.

Off-margin high is the set of Values [ $\$ 0.00$ to $\$ 2.50]$.

Off-margin mid is the set of Values [ $\$-2.50$ to $\$ 0.00]$.

Off-margin low is the set of Values [ $\$-5.00$ to $\$-2.50]$.

${ }^{* *}$ significant at 0.01 .
} 